\title{
Photooxidation of Parenteral Multivitamins Induces Hepatic Steatosis in a Neonatal Guinea Pig Model of Intravenous Nutrition
}

\author{
PHILIPPE CHESSEX, JEAN-CLAUDE LAVOIE, THÉRÈSE ROULEAU, PIERRE BROCHU, \\ PATRICK ST-LOUIS, EMILE LÉVY, AND FERNANDO ALVAREZ \\ Perinatal Service and Research Center, Hôpital Ste-Justine, Department of Pediatrics, University of \\ Montreal, Montreal, Quebec, Canada
}

\begin{abstract}
Photooxidation of multivitamin solutions results in the generation of peroxides. Because peroxides are associated with hepatic steatosis and fibrosis as well as cholestasis, we questioned whether multivitamins are implicated in hepatic complications of parenteral nutrition. Guinea pig pups were assigned to groups receiving intravenously either total parenteral nutrition, photo-protected or not, or a control solution (5\% dextrose + $0.45 \% \mathrm{NaCl}$ ) supplemented with either a) multivitamins; b) photo-protected multivitamins; c) multivitamins without riboflavin; or d) peroxides $\left(\mathrm{H}_{2} \mathrm{O}_{2}\right.$, tert-butylhydroperoxide). After $4 \mathrm{~d}$, liver was sampled for histology and isoprostane- $\mathrm{F}_{2 \alpha}$ levels, a marker of radical attack. Multivitamins as well as total parenteral nutrition were associated with steatosis (scored $0-4)$, the severity of which was reduced $(p<0.05)$ by photo protection. Although $\mathrm{H}_{2} \mathrm{O}_{2}$ is the major peroxide contaminating multivitamins, it did not induce steatosis scores different than the controls. Compared with controls, hepatic isoprostane- $\mathrm{F}_{2 \alpha}$ content increased in animals infused with $\mathrm{H}_{2} \mathrm{O}_{2}(p<0.05)$, but not in those infused with Multi-12 pediatric multivitamins or total parenteral
\end{abstract}

\section{ABSTRACT}

nutrition. Results suggest that peroxides and/or free radicals are not mediators of the induction of steatosis observed with infusion of photo-exposed multivitamins, as there was no correspondence between histologic findings and hepatic levels of isoprostanes. It is suspected that a component of the multivitamin solution becomes hepato-toxic after photo-exposure, as indicated by the protective effect observed when withdrawing riboflavin. Photooxidation of multivitamins might be the common link between reports involving amino acids, lipids, and light exposure in the ethiology of hepatic complications of parenteral nutrition. (Pediatr Res 52: 958-963, 2002)
C, control
Abbreviations
CVI, Cernevit multivitamins
MVP, Multi-12 pediatric multivitamins
MVI, pediatric multivitamins
TBH, tert-butylhydroperoxide
TPN, total parenteral nutrition

Exposure of TPN solutions to light is linked to alterations in hepatobiliary function and histology in a perfused liver model (1) as well as in vivo (2). In the presence of light, the parenteral multivitamin preparation is the site of reactions between oxygen and electron donors, resulting in the generation of peroxides. Hydrogen peroxide $\left(\mathrm{H}_{2} \mathrm{O}_{2}\right)$, which is regarded as a key element in the oxygen toxicity of the cell, represents over $80 \%$ of peroxides generated in multivitamins (3). Organic peroxides have also been reported to contaminate solutions of parenteral nutrition (3-6). In parenterally fed neonates, the exposure of multivitamins to daylight is associated with an infused perox-

Received July 3, 2001; accepted July 17, 2002.

Correspondence: Jean-Claude Lavoie, Ph.D., Research Centre, Hospital Sainte-Justine, 3175 Chemin Côte Ste-Catherine, Montreal, QC, Canada, H3T 1C5; e-mail: jclavoie@justine.umontreal.ca

Supported in part by a grant from Sabex (Boucherville, Québec, Canada) and by institutional funding from the Research Centre of Hospital Sainte-Justine.

DOI: 10.1203/01.PDR.0000034236.69144.AC ide load and its urinary excretion (7). Peroxides have been linked to hepatic steatosis (8) and fibrosis (9), as well as cholestasis (10). Multivitamins and peroxides induce the same oxidant response in the lungs of guinea pig pups (11). The relative liver weight of these animals was $40 \%$ higher than controls (12), and histology revealed the presence of hepatic steatosis. We hypothesize that multivitamins might account for part of the role of light in TPN-related liver complications.

Because of the catalytic role of photo-excited riboflavin (13), protection of TPN solutions from exposure to light results in a decreased generation of peroxides and a reduction in their rate of infusion (3). As $\mathrm{H}_{2} \mathrm{O}_{2}$ is a weak oxidant, it can accumulate to high concentrations owing to its stability, or it can also be converted into reactive species (14) in the presence of transition metals (15, 16) such as $\mathrm{Fe}^{2+}$ and $\mathrm{Cu}^{+}$via the Fenton/Haber-Weiss reactions. Furthermore, the antioxidant components of the parenteral multivitamins would be expected to protect against the free radicals derived from peroxides generated in TPN solutions (12). 
The objective of this study was to evaluate the role of multivitamins in TPN-related liver complications as documented by histology and to separate the effect of light exposure from that of peroxides and/or free radicals.

\section{METHODS}

Animal model. Under ketamine/xylazine, 3-d-old guinea pig pups (Charles River, Montreal, Quebec, Canada) were fitted with a $0.4-\mathrm{mm}$ polyurethane catheter (Luther Medical Products, Tustin, CA, U.S.A.) in the external jugular vein and exteriorized in the scapular region. The catheter was connected to a flow-through system permitting mobility of the animals, which were housed separately in plastic boxes with wire mesh bottoms. The animals were kept in a thermo-controlled environment with a 12-h light/dark cycle, and they were fed exclusively intravenously at $240 \mathrm{~mL} / \mathrm{kg} / \mathrm{d}$. After $4 \mathrm{~d}$, the animals were killed and the liver was divided into aliquots with samples kept in formol for histology or minced and stored at $-80^{\circ} \mathrm{C}$ until analysis of triglycerides and isoprostanes, an index of radical attack (17). The study was performed in accordance with the guidelines of the institutional animal committee.

This animal model was chosen because of our previous unpublished observation of hepatic steatosis in guinea pig pups. To verify whether this steatosis could be prevented by photoprotection, the same experimental conditions had to be replicated.

Protocols. To separate the effect of multivitamins and light, animals were infused with one of the following regimens containing a multivitamin solution at a concentration similar to the one used in neonatal parenteral nutrition. Photoprotection was achieved by preparing the solutions in darkness and covering the infusion set with opaque material and using photo-protected intravenous tubing (13) provided graciously by Baxter Canada.

MVP + light: 1\% (vol/vol) MVP (Sabex, Boucherville, Quebec, Canada) unprotected from ambient light, diluted in the control solution $(50 \mathrm{~g} / \mathrm{L}$ dextrose $+4.5 \mathrm{~g} / \mathrm{L} \mathrm{NaCl}+1$ unit heparin $/ \mathrm{mL}$ ); $5 \mathrm{~mL}$ of MVP contains the following: vitamin A, $2300 \mathrm{IU}$; vitamin D, $400 \mathrm{IU}$; $\alpha$-tocopherol, 7 IU; vitamin K, $200 \mu \mathrm{g}$; ascorbate, $80 \mathrm{mg}$; thiamine, $1.2 \mathrm{mg}$; riboflavin, 1.4 $\mathrm{mg}$; pyridoxine, $1.0 \mathrm{mg}$; pantothenate, $5 \mathrm{mg}$; folate, $0.14 \mathrm{mg}$; cyanocobalamin, $1 \mu \mathrm{g}$; nicotinamide, $17 \mu \mathrm{g}$; biotin, $20 \mu \mathrm{g}$; and the additives mannitol and polysorbates as emulsifiers.

MVP - light: $1 \%$ (vol/vol) MVP photo-protected, diluted in the control solution.

$T P N+$ light: Two solutions unprotected from ambient light were infused in a "piggy-backed" set-up mixed close to the infusion site: a) control $+9.6 \mathrm{~g} / \mathrm{kg} / \mathrm{d}$ amino acids (Travasol, Baxter Canada, Mississauga, Ontario, Canada) $+2 \%$ MVP at $120 \mathrm{~mL} / \mathrm{kg} / \mathrm{d} ; \mathrm{b}$ ) control $+9.6 \mathrm{~g} / \mathrm{kg} / \mathrm{d}$ amino acids $+7.6 \mathrm{~g} / \mathrm{kg} / \mathrm{d}$ lipids (Intralipid 20\%, Pharmacia, Peapack, NJ, U.S.A.) at 120 $\mathrm{mL} / \mathrm{kg} / \mathrm{d}$; for a final concentration (at $240 \mathrm{~mL} / \mathrm{kg} / \mathrm{d}$ ) of $1 \%$ MVP $+4.8 \mathrm{~g} / \mathrm{kg} / \mathrm{d}$ amino acids $+3.8 \mathrm{~g} / \mathrm{kg} / \mathrm{d}$ lipids. The composition of the TPN regimen was derived from recommendations for studies in adult guinea pigs (18).
TPN (-) light: The same TPN preparation protected from ambient light.

To evaluate whether the effects observed with MVP and TPN were related to peroxides and/or free radicals, other groups of animals were infused with one of the following solutions:

$C$ (control): $50 \mathrm{~g} / \mathrm{L}$ dextrose $+4.5 \mathrm{~g} / \mathrm{L} \mathrm{NaCl}+1$ unit heparin $/ \mathrm{mL}$.

$\mathrm{H}_{2} \mathrm{O}_{2}$ : control +200 or $500 \mu \mathrm{M} \mathrm{H}_{2} \mathrm{O}_{2}$ (Aldrich Chemical, Milwaukee, WI, U.S.) $(208 \pm 15$ and $500 \pm 20 \mu \mathrm{M}$ measured).

TBH: control $+50 \mu \mathrm{M}$ TBH (Aldrich Chemical) $(47 \pm 1$ measured).

To isolate the role of riboflavin and to determine whether the effects of multivitamins were specific to MVP, other groups of animals were infused with one of the following regimens:

$C$ : same as above

$M V P+$ light: as described above in protocol 1.

MVP + light without riboflavin: 1\% MVP prepared by Sabex without riboflavin, unprotected from ambient light and diluted in the control solution.

MVI + light: 1\% (vol/vol) MVI (Aventis, Strasbourg, France) unprotected from ambient light and diluted in the control solution; $5 \mathrm{~mL}$ solution reconstituted from powder contains the following: vitamin A, $2300 \mathrm{IU}$; vitamin D, $400 \mathrm{IU}$; $\alpha$-tocopherol, $7 \mathrm{IU}$; vitamin $\mathrm{K}, 200 \mu \mathrm{g}$; ascorbate, $80 \mathrm{mg}$; thiamine, $1.2 \mathrm{mg}$; riboflavin, $1.4 \mathrm{mg}$; pyridoxine, $1.0 \mathrm{mg}$; pantothenate, $5 \mathrm{mg}$; folate, $0.14 \mathrm{mg}$; cyanocobalamin, $1 \mu \mathrm{g}$; nicotinamide, $17 \mathrm{mg}$; biotin, $20 \mu \mathrm{g}$; and the additives BHA, BHT, and mannitol, as well as polysorbates as emulsifiers.

CVI + light: $1 \%$ (vol/vol) Cernevit (Baxter Canada) unprotected from ambient light and diluted in the control solution; the $5 \mathrm{~mL}$ solution contains vitamin A, $3500 \mathrm{IU}$; vitamin D, 220 IU; $\alpha$-tocopherol, $11.2 \mathrm{IU}$; ascorbate, $125 \mathrm{mg}$; thiamine, 3.51 $\mathrm{mg}$; riboflavin, $4.14 \mathrm{mg}$; pyridoxine, $4.53 \mathrm{mg}$; pantothenate, $17.25 \mathrm{mg}$; folate, $414 \mu \mathrm{g}$; cyanocobalamin, $6 \mu \mathrm{g}$; nicotinamide, $46 \mathrm{mg}$; biotin, $69 \mu \mathrm{g}$; and the additives glycocoll, glycocholic acid, and soy bean lecithin.

Histology. After staining with hematoxylin-eosin, hepatic histology was performed, and the severity of steatosis scored 0-4 (Fig. 1) by a pathologist (P.B.) and a hepatologist (F.A.) unaware of the intravenous regimen received. The scores indicated the following: $0=$ normal hepatic structure; $1=$ presence of visible fat vacuoles in single, isolated hepatocytes; $2=$ focal fatty changes of heterogeneous lobular distribution; 3 = diffuse fatty changes with rare "fat-free" zones; $4=$ diffused fatty changes, without "fat-free" zones.

Analytical procedures. Peroxides were measured with the xylenol orange technique (19), as described previously. This chemical assay, which measures $\mathrm{H}_{2} \mathrm{O}_{2}$ as well as organic peroxides $(19,20)$ was validated for TPN solutions using an enzymatic assay (21). The mean peroxide levels for three samples were MVI $=295 \pm 8 \mu \mathrm{M}$; CVI $=358 \pm 28 \mu \mathrm{M}$; $\mathrm{MVP}=198 \pm 14 \mu \mathrm{M} ;$ MVP photo-protected $=131 \pm 10$ $\mu \mathrm{M}$; and MVP without riboflavin $=129 \pm 3 \mu \mathrm{M}$. Isoprostane $\mathrm{F}_{2 \alpha}$ was measured using a commercial enzyme immunoassay kit (Cayman Chemical, Ann Arbor, MI, U.S.A.). Liver triglyc- 


\section{HEPATIC HISTOLOGY (x250)}
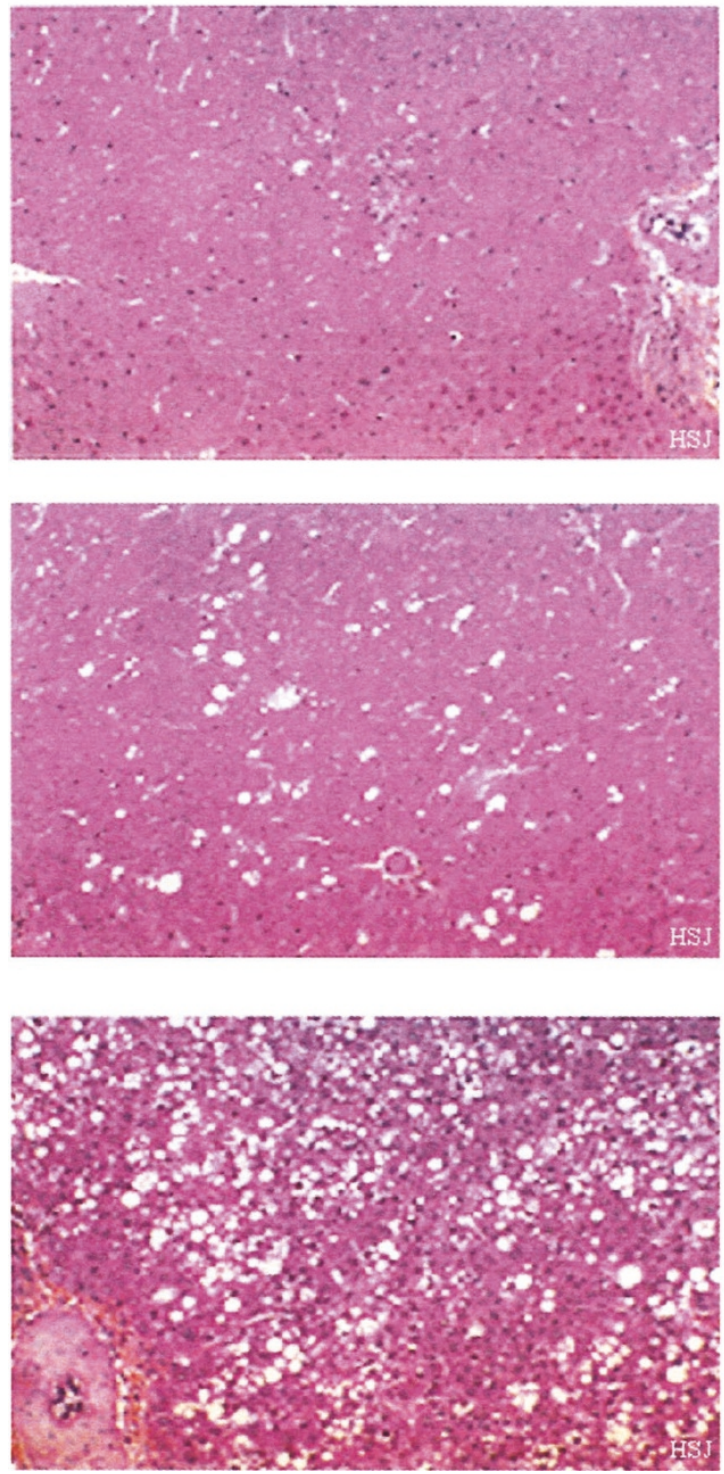

\section{Steatosis \\ scored 0 to 4}

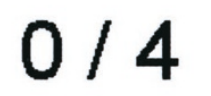

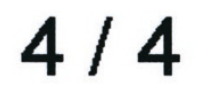

Figure 1. Hepatic histology $(\times 250)$ illustrating scores of severity of steatosis scored from 0 to 4 .

eride levels were measured enzymatically using commercial kits (Roche Diagnostics, Laval, Quebec, Canada).

Statistical analysis. All results are presented as mean \pm SEM. Results for steatosis were analyzed by Mann-Whitney test for nonparametric data. Anthropometric characteristics of the animals (Table 1) and hepatic isoprostane $\mathrm{F}_{2 \alpha}$ were compared by ANOVA after transformation (natural logarithm) to ensure homoscedasticity as determined by Bartlett's chisquare. The level of significance was set at $p<0.05$.

\section{RESULTS}

There was no difference in the initial body weight of the animals within the various protocols (Table 1). In the first protocol, photo-protection was associated with a significantly lower $(p<0.05)$ relative liver weight (percentage of body weight).
Animals receiving photo-exposed multivitamin solutions infused as an admixture to $\mathrm{C}$ or to TPN presented varying degrees of hepatic steatosis. In cases of hepatic steatosis scored $2 / 4$, the macrovesicular fatty changes were mainly observed in lobular zones 3 and 2. In specimens evaluated as showing scores of 3 to $4 / 4$, nodules of fat-laden hepatocytes gathered into a circumscribed nodule. Whatever the steatosis score recorded, no inflammatory infiltration or enlargement of portal tracts were observed. Multivitamins as well as TPN were associated with steatosis (scored $0-4$ ), the severity of which was reduced $(p<0.05)$ by photo-protection (Fig. $2 A)$. Compared with MVP, the apparently lower score of hepatic steatosis observed in animals receiving TPN regimens did not reach statistical significance. These histologic findings were not accompanied by corresponding changes in hepatic isoprostane levels (Fig. 2B). Animals receiving photo-protected solutions 
Table 1. Anthropometric characteristics of the animals

\begin{tabular}{|c|c|c|c|c|}
\hline Intravenous solutions & No. & $\begin{array}{l}\text { Initial body } \\
\text { weight }(\mathrm{g})\end{array}$ & $\begin{array}{c}\text { Change in } \\
\text { body weight (\%) }\end{array}$ & $\begin{array}{l}\text { Relative liver weight } \\
\text { (\% body weight })\end{array}$ \\
\hline \multicolumn{5}{|l|}{ Protocol I } \\
\hline MVP - light & 9 & $116 \pm 6$ & $-15 \pm 3$ & $3.1 \pm 0.1$ \\
\hline MVP + light & 9 & $120 \pm 4$ & $-19 \pm 2$ & $3.4 \pm 0.1$ \\
\hline TPN - light & 6 & $124 \pm 7$ & $-15 \pm 2$ & $3.4 \pm 0.2$ \\
\hline TPN + light & 6 & $128 \pm 6$ & $-15 \pm 2$ & $3.9 \pm 0.2$ \\
\hline \multicolumn{5}{|l|}{ Protocol II } \\
\hline $\mathrm{C}$ & 10 & $117 \pm 6$ & $-22 \pm 3$ & $3.2 \pm 0.1$ \\
\hline ТВН $50 \mu \mathrm{M}$ & 4 & $121 \pm 10$ & $-11 \pm 4$ & $3.3 \pm 0.1$ \\
\hline $\mathrm{H}_{2} \mathrm{O}_{2} 200 \mu \mathrm{M}$ & 6 & $115 \pm 1$ & $-19 \pm 3$ & $3.4 \pm 0.1$ \\
\hline $\mathrm{H}_{2} \mathrm{O}_{2} 500 \mu \mathrm{M}$ & 8 & $118 \pm 5$ & $-19 \pm 3$ & $3.2 \pm 0.1$ \\
\hline \multicolumn{5}{|l|}{ Protocol III } \\
\hline $\mathrm{C}$ & 10 & $107 \pm 7$ & $-25 \pm 4$ & $3.4 \pm 0.1$ \\
\hline MVP + light & 9 & $109 \pm 4$ & $-13 \pm 2$ & $3.3 \pm 0.1$ \\
\hline MVP + light - riboflavin & 9 & $129 \pm 2$ & $-15 \pm 2$ & $3.4 \pm 0.1$ \\
\hline $\mathrm{CVI}+$ light & 11 & $101 \pm 3$ & $-9 \pm 2$ & $3.1 \pm 0.3$ \\
\hline MVI + light & 5 & $114 \pm 4$ & $-11 \pm 3$ & $3.1 \pm 0.3$ \\
\hline
\end{tabular}

Results are expressed as mean \pm SEM; change in body weight occurred over the $4 \mathrm{~d}$ of the protocol. C, control $=0.45 \% \mathrm{NaCl}+5 \% \mathrm{dextrose}$; MVP, $1 \%$ Multi-12 Pediatric; MVI, 1\% MVI Pediatric; CVI, 1\% Cernevit; (+) light, exposed to ambient light; (-) light, photoprotected.

A

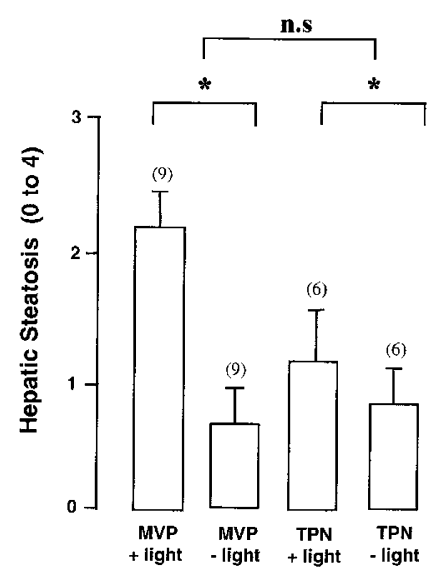

B

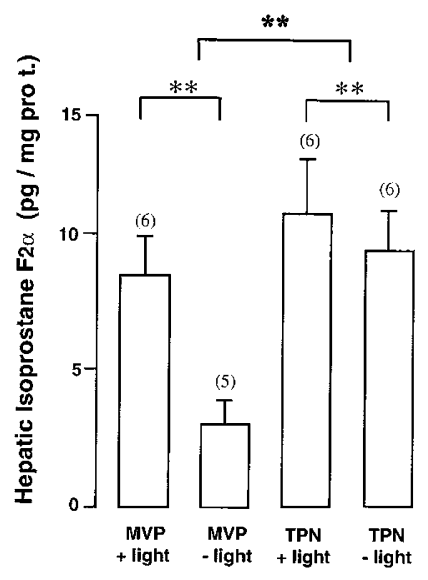

Figure 2. Effect of parenteral multivitamins (MVP), TPN (5\% dextrose + $0.45 \% \mathrm{NaCl}+$ amino acids + lipids $+\mathrm{MVP}$ ) and light exposure ( \pm light) on $(A)$ the severity of hepatic steatosis (scored $0-4)$ and $(B)$ hepatic isoprostane $\mathrm{F}_{2 \alpha}$. Multivitamins and TPN were associated with steatosis, the severity of which was reduced by photo-protection ( - light). Photo-protection decreased significantly isoprostane levels, which did not correspond with the severity of steatosis as TPN induced significantly higher levels of this eicosanoid marker of free radical attack. Each bar represents the mean \pm SEM (number of samples). ${ }^{*} p<0.05, * * p<0.01$.

had significantly lower isoprostane levels $(p<0.01)$. However, compared with MVP, those animals receiving TPN exhibited significantly higher $(p<0.01)$ hepatic levels of this eicosanoid marker of radical attack.

Figure 3, $A$ and $B$, illustrates that the oxidant load induced by peroxides generated in light-exposed multivitamins or TPN did not account for the induction of hepatic steatosis. $\mathrm{H}_{2} \mathrm{O}_{2}$ infused at concentrations found in MVP or TPN (3) did not induce a score of steatosis significantly higher than the controls (Fig. $3 A)$, which exhibited a lower score $(p<0.01)$ than animals receiving MVP exposed to light (Fig. 4). Results obtained with TBH infused at a concentration compatible with levels of organic peroxides detected in MVI (3) were similar to $\mathrm{C}$ and $\mathrm{H}_{2} \mathrm{O}_{2}$. The results presented in Figure $3 B$ support the conten-

A
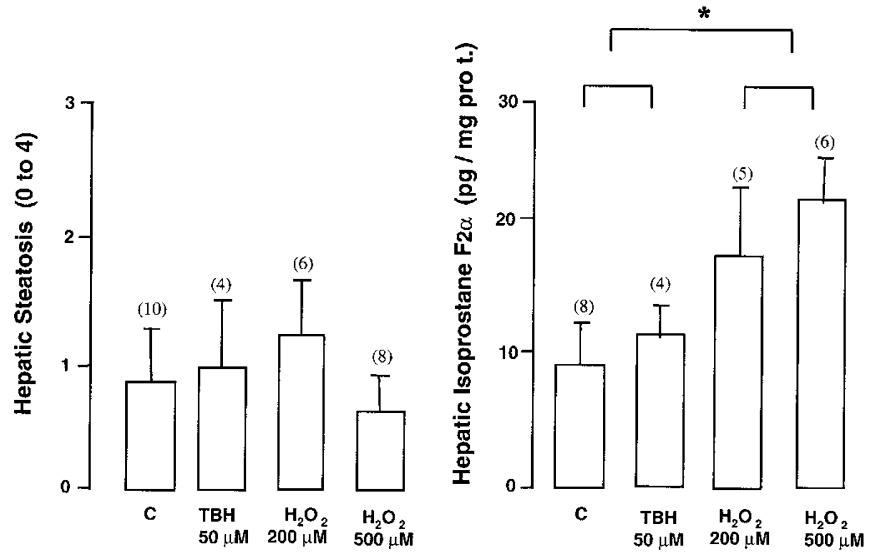

Figure 3. Effect of infused $\mathrm{H}_{2} \mathrm{O}_{2}$ and TBH on $(A)$ the severity of steatosis and $(B)$ hepatic isoprostane $\mathrm{F}_{2 \alpha} \cdot \mathrm{H}_{2} \mathrm{O}_{2}$ and TBH infused in a range of concentrations generated in multivitamins did not induce scores of hepatic steatosis higher than the controls $(\mathrm{C}=5 \%$ dextrose $+0.45 \% \mathrm{NaCl}) . \mathrm{H}_{2} \mathrm{O}_{2}$ induced an oxidant load, as it had a positive effect on levels of isoprostane $\mathrm{F}_{2 \alpha}$. Each bar represents the mean $\pm \mathrm{SEM}$ (number of samples). ${ }^{*} p<0.05$.

tion that the infused peroxides carried an oxidant load. Indeed, the levels of hepatic isoprostanes found in animals receiving $\mathrm{H}_{2} \mathrm{O}_{2}$ were significantly higher than controls (Fig. $3 \mathrm{~B}$ ) and between $50 \%$ and $100 \%$ higher than in animals receiving multivitamin solutions inducing a score of steatosis $>2$ (Fig. $2 B)$.

When exposed to ambient light, the different multivitamin solutions evaluated in this study (MVP, MVI, CVI) induced a similar score of hepatic steatosis, which was significantly higher $(p<0.01)$ than the score recorded in $\mathrm{C}$ or in the animals receiving MVP without riboflavin exposed to light (Fig. 4). The latter two groups exhibited a similar low score of hepatic steatosis.

Hepatic steatosis was confirmed by documenting higher ( $p$ $<0.05)$ liver triglyceride levels $(0.81 \pm 0.32$ versus $0.23 \pm$ $0.07 \mathrm{mg} / \mathrm{mg}$ protein) in a subgroup of animals with overt 


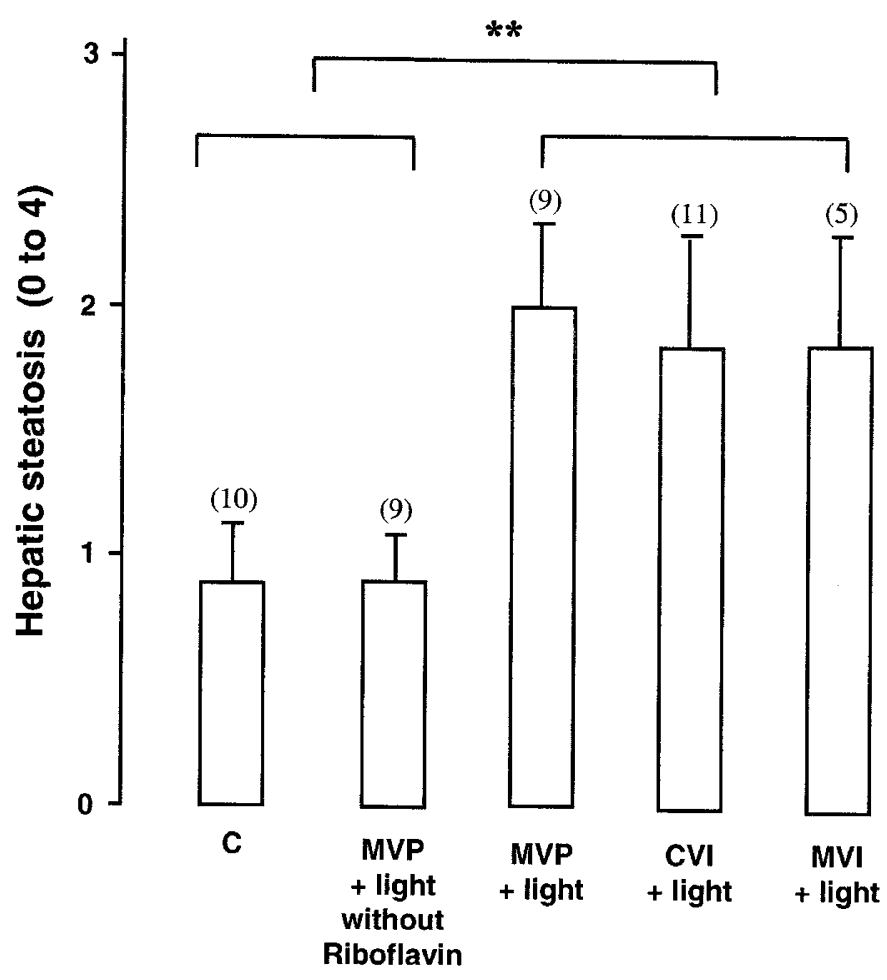

Figure 4. Compared with the control $(\mathrm{C}=5 \%$ dextrose $+0.45 \% \mathrm{NaCl})$, the photo-exposed (+ light) multivitamin preparations (MVP, MVI, CVI) enhanced hepatic steatosis (scored $0-4$ ). The role of riboflavin on the effect induced by light exposure was tested using a preparation devoid of this photo-excitable vitamin (MVP without riboflavin). Each bar represents the mean \pm SEM (number of samples). ${ }^{*} p<0.05,{ }^{* *} p<0.01$.

steatosis (score 2-4: $3.1 \pm 0.3, n=6$ ) compared with those with no or little steatosis (score 0 or 1: $0.7 \pm 0.1, n=13$ ).

\section{DISCUSSION}

Steatosis is a hepatic micro- or macrovesicular fat accumulation associated with metabolic diseases, diabetes, obesity (22), drugs and toxins (23), surgical procedures, and parenteral nutrition (21), as well as nonalcoholic steato-hepatitis, in which case an oxidant stress is thought to play a pathogenic role (24). TPN-related hepatic dysfunctions (25) have been linked to oxidant stress $(26,27)$ as well as genetic $(28,29)$, nutritional, environmental, and inflammatory factors (23). More specifically, the following nutritional factors have been associated with steatosis and/or cholestasis: enteral starvation $(30,31)$, an amino acid imbalance $(32,33)$, photo-oxidized products of amino acids $(11,12,34)$, an excessive infusion of glucose (35) or lipids (36), a carbohydrate to nitrogen imbalance $(37,38)$, and the source of infused lipids (39).

The results of the present study suggest that TPN, when exposed to light, induces hepatic steatosis. The fact that this effect of light is linked to MVP points toward an oxidant stress $(11,40)$. The ethiology of this steatosis might be explained by infused oxidants increasing lipogenesis, or decreasing lipid transport (2) and oxidative metabolism (41, 42). However, the results suggest that peroxides and/or free radical are not mediators of the induction of steatosis observed with infusion of photo-exposed multivitamins, as there was no correspondence between histologic findings and hepatic levels of isoprostanes.

Starvation might account for the hepatic steatosis observed when glucose is the only source of energy provided with MVP. TPN prevented only partially the steatosis induced by MVP. This effect of TPN could be explained by the lipid emulsion acting either as a shield protecting the multivitamins against the effect of light or as a substrate improving the nutritional status. Since the effect of light was also observed with TPN, the later explanation is more likely. Among the nutritional factors contributing to steatosis, the carbohydrate to nitrogen imbalance might be implicated. However, light protection reduced the risk of steatosis even in animals receiving only dextrose + MVP. In rats, diets without choline are used to induce steatosis (43) and in humans, steatosis is corrected by giving choline (44). Choline is an important component of phosphocholine, which is involved in lipid transport. Therefore, the $99 \mathrm{mg} \%$ phosphocholine provided to the guinea pigs by the lipid emulsion might account for this observation.

Various sources of multivitamins (MVP, MVI, and CVI) were found to induce the same score of steatosis despite differences in vitamin concentrations, in additives (polysorbates, BHT, BHA, mannitol), in means of conservation (powder versus liquid form) or in levels of $\mathrm{H}_{2} \mathrm{O}_{2}$. This is further evidence that infused $\mathrm{H}_{2} \mathrm{O}_{2}$ is not implicated in this common hepatic complication of TPN. Although TBH was not found to be associated with steatosis, this does not preclude a possible role for further organic peroxides generated by photooxidation. It is suspected that a component of the multivitamin solution becomes hepato-toxic after light exposure as indicated by the protective effect observed when withdrawing riboflavin. Apart from the generation of peroxides, photo-excited riboflavin also produces strongly oxidizing triplets. A direct effect of activated riboflavin on the induction of steatosis cannot be excluded. Photo-oxidation of multivitamins might be the common link between reports involving amino acids (34), lipids (39), and light exposure $(1,2)$ in the ethiology of hepatic complications of parenteral nutrition.

Multivitamins and $\mathrm{H}_{2} \mathrm{O}_{2}$ induced similar responses on markers of oxidation measured in the lungs $(11,40)$, whereas in the liver they induced separate effects on hepatic isoprostane levels as well as on steatosis. After their infusion, multivitamins and peroxides will transit through the lungs before reaching the liver. This could explain in part why the responses elicited in these tissues are different. However, this discrepancy does not result from peroxides being consumed before reaching the liver, as they did cause a marked increase in hepatic isoprostane levels.

It is questionable whether our observations made in a 4-d infusion model can be extrapolated to subjects receiving complete TPN for a longer time, or to patients with low antiperoxide defenses such as premature infants (22). The development of hepatic steatosis observed in the present study could be related specifically to the animal model. Guinea pig tissues other than the brain do not use much glucose, and they do not respond to insulin by increasing glucose uptake. It is therefore important to recognize that interspecies differences make extrapolations to the clinical situation hazardous (21). 
In summary, multivitamins exposed to light induce hepatic steatosis. This complication of TPN is not related to the level of hydrogen peroxide or to a radical attack. A photosensitive component of the multivitamin solution is suspected. In spite of its peroxide load, MVP carries antioxidant properties (12) as documented by the 3-fold lower hepatic isoprostane levels observed with photo-protected MVP (Fig. 2B) compared with $\mathrm{C}$ (Fig. 3B). Because free radicals are produced in response to various sources of oxidant stress, improving free radical scavenging properties of MVP by photo-protection (Fig. 2B) may in itself be of biologic significance.

\section{REFERENCES}

1. Shattuck KE, Bhatia J, Grinnell C, Rassin DK 1995 The effect of light exposure on the in vitro hepatic response to an amino acid-vitamin solution. JPEN J Parenteral Enteral Nutr 19:398-402

2. Bhatia J, Moslen T, Haque AK, McCleery R, Rassin DK 1993 Total parentera nutrition-associated alterations in hepatobiliary function and histology in rats: is light exposure a clue? Pediatr Res 33:487-492

3. Lavoie JC, Bélanger S, Spalinger M, Chessex P 1997 Admixture of a multivitamin preparation to parenteral nutrition: the major contributor to in vitro generation of peroxides. Pediatrics 99:E61-E70

4. Laborie S, Lavoie JC, Chessex P 1998 Paradoxical role of ascorbic acid and riboflavin in solutions of total parenteral nutrition: implications in photo-induced peroxide generation. Pediatr Res 43:601-606

5. Helbock HJ, Motchnick PA, Ames BN 1993 Toxic hydroperoxides in intravenous lipid emulsions used in preterm infants. Pediatrics 91:83-88

6. Neuzil J, Darlow BA, Inder TE, Sluis KB, Winterbourn CC, Stocker R 1995 Oxidation of parenteral lipid emulsion by ambiant and phototherapy lights: potential toxicity of routine parenteral feeding. J Pediatr 126:785-790

7. Laborie S, Lavoie JC, Chessex P 2000 Increased urinary peroxides in newborn infants receiving parenteral nutrition exposed to light. J Pediatr 136:628-632

8. May JM, de Haën C 1979 The insulin-like effect of hydrogen peroxide on pathways of lipid synthesis in rat adipocytes. J Biol Chem 24:9017-9021

9. Greenwel P, Dominguez-Rosales JA, Mavi G, Rivas-Estilla M, Rojkin M 2000 Hydrogen peroxide: a link between acetaldehyde-elicited $\alpha(1)$ collagen gene upregulation and oxidative stress in mouse hepatic stellate cells. Hepatology 31:109116

10. Panozzo MP, Basso D, Balint L, Biasin MR, Bonvicini P, Metus P, Infantolino D, Plebani M 1995 Altered lipid peroxidation/glutathione ratio in experimental extrahepatic cholestasis. Clin Exp Pharm Physiol 22:266-271

11. Lavoie JC, Laborie S, Rouleau T, Spalinger M, Chessex P 2000 Peroxide-like response in lungs of newborn guinea pigs following the parenteral infusion of a multivitamin preparation. Biochem Pharmacol 60:1297-1303

12. Chessex P, Lavoie JC, Laborie S, Rouleau T 2001 Parenteral multivitamin supplementation induces oxidant as well as antioxidant responses in the liver of newborn guinea pigs. J Pediatr Gastroenterol Nutr 32:316-321

13. Laborie S, Lavoie JC, Pineault M, Chessex P 1999 Protecting solutions of parenteral nutrition from peroxidation. JPEN J Parenteral Enteral Nutr 23:104-108

14. Sasaki K, Bannai S, Makino N 1998 Kinetics of hydrogen peroxide elimination by human umbilical vein endothelial cells in culture. Biochim Biophys Acta 1380:275288

15. Moison RMW, Palinckx JJS, Roest M, Houdkamp E, Berger HM 1993 Induction of lipid peroxidation of pulmonary surfactant by plasma of preterm babies. Lancet 341:79-82

16. Lavoie JC, Chessex P 1997 Bound iron admixture prevents the spontaneous generation of peroxides in total parenteral nutrition solutions. J Pediatr Gastroenterol Nutr 25:307-311

17. Roberts LJ, Morrow JD 2000 Measurement of F(2)-isoprostanes as an index of oxidative stress in vivo. Free Radic Biol Med 28:505-513
18. Lu CJH, Redmond D, Baggs RB, Schnechter A, Gasiewicz TA 1986 Growth and hepatic composition in the guinea-pig after long term parenteral alimentation. Am J Physiol 251:R388-R397

19. Jiang ZY, Woollard ACS, Wolff SP 1991 Lipid hydroperoxide measurement by oxidation of $\mathrm{Fe}^{2+}$ in the presence of xylenol orange. Comparison with the TBA assay and an iodometric method. Lipids 26:853-856

20. Lavoie JC, Lachance C, Chessex P 1994 Antiperoxyde activity of sodium metabisulfite: a double-edged sword. Biochem Pharmacol 47:871-876

21. Quigley EMM, Arsh MN, Shaffer JL, Markin RS 1993 Hepatobiliary complications of total parenteral nutrition. Gastroenterology 104:286-301

22. Vajro P, Franzese A, Valeiro G, Iannucci M, Aragione N 2000 Lack of efficacy of ursodeoxycholic acid for the treatment of liver abnormalities in obese children. J Pediatr 136:739-745

23. Trauner M, Fickert P, Stauber R 1999 Inflammation induced cholestasis. J Gastroenterol Hepatol 14:946-959

24. Day C, James P 1998 Steatohepatitis: a tale of two "hits"? Gastroenterology 114:842 845

25. Teitelbaum D 1997 Parenteral nutrition-associated cholestasis. Curr Opin Pediatr 9:270-275

26. Bolder U, Ton-Nu HT, Schteingart CD, Frick E, Hofmann AF 1997 Hepatocyte transport of bile acids and organic anions in endotoxemic rats: impaired uptake and secretion. Gastroenterology 112:214-225

27. Sokol RJ, Taylor SF, Devereaux MW, Khandwala R, Sondheimer NJ, Shikes RH, Mierau G 1996 Hepatic oxidant injury and glutathione depletion during total parenteral nutrition in weanling rats. Am J Physiol 270:G691-G700

28. Balistreri WF 1991 Fetal and neonatal bile acid synthesis and metabolism-clinical implications. J Inherit Metab Dis 14:459-477

29. Suchy FJ, Sippel CJ, Ananthanarayanan M 1997 Bile acid transport across the hepatocyte canalicular membrane. FASEB J 11:199-205

30. Lucas A, Bloom SR, Aynsley-Green A 1986 Gut hormones and 'minimal enteral feeding.' Acta Paediatr Scand 75:719-723

31. Jones RS, Grossman MI 1971 The choleretic effects of glucacon and secretin in the dog. Gastroenterology 60:64-68

32. Moss RL, Haynes AL, Patuszyn A, Glew RH 1999 Methionine infusion reproduces liver injury of parenteral nutrition cholestasis. Pediatr Res 45:664-668

33. Belli DC, Fournier LA, Lepage G, Yousef I, Weber AM, Turchweber B, Roy CC 1987 Total parenteral nutrition-associated cholestasis in rats: comparison of different amino acid mixtures. JPEN J Parenteral Enteral Nutr 11:67-73

34. Bathia J, Mims LC, Rorsel RA 1982 The effect of phototherapy on amino acid solutions containing multivitamins. J Pediatr 96:284-286

35. Lowry SF, Brennan MF 1979 Abnormal liver function during parenteral nutrition: relation to infusion excess. J Surg Res 26:300-307

36. Allardyce DB 1982 Cholestasis caused by lipid emulsions. Surg Gynecol Obstet 154:641-647

37. Keim NL 1987 Nutritional effects of hepatic steatosis induced by parenteral nutrition in rats. JPEN J Parenteral Enteral Nutr 1:18-22

38. Ikeda Y, Soda S, Okada A, Kawashima Y 1979 Are hepatomegaly and jaundice attributable to "glucose overload"? Acta Chir Scand suppl 494:170-172

39. Van Aerde J, Duerksen DR, Gramlich L, Medings JB, Chan G, Thomson ABR, Clandinin MT 1999 Intravenous fish oil emulsion attenuates total parenteral nutritioninduced choestatsis in newborn piglets. Pediatr Res 45:202-208

40. Lavoie JC, Rouleau T, Gagnon C, Chessex P 2002 Photoprotection prevents TPNinduced procollagen mRNA in newborn guinea pigs. Free Radic Biol Med 33:512520

41. Fromenty B, Pessayre D 1995 Inhibition of mitochondrial beta-oxidation as a mechanism of hepatotoxicity. Pharmacol Ther 67:101-154

42. Abernathy F, Pacht E 1995 Alteration of adenosine triphosphate and other nucleotides after sublethal oxidant injury to rat type II alveolar epithelial cells. Am J Med Sci 309:140-145

43. Grattagliano I, Vendemiale G, Caraceni P, Domenicali M, Nardo B, Cavallari A, Trevisani F, Bernardi M, Altomare E 2000 Starvation impairs antioxidant defence in fatty livers of rats fed a choline-deficient diet. J Nutr 130:2131-2136

44. Buchman AL, Dubin MD, Moukarzel AA, Jenden DJ, Roch M, Rice KM, Gornbein J, Ament ME 1995 Choline deficiency: a cause of hepatic steatosis during parenteral nutrition that can be reversed with intravenous choline supplementation. Hepatology 22:1399-1403 